\title{
Incorporation of bioclimatic conditions in architectural projects: a case study of the Solar Hemicycle building, Madrid, Spain
}

\author{
E. Vazquez ${ }^{1}$, M. Brandão ${ }^{1}$, S. Rola ${ }^{2}$, L. Alves ${ }^{3}$, M. Freitas ${ }^{4}$ \\ \& L. Pinguelli Rosa ${ }^{4}$ \\ ${ }^{1}$ Department of Civil Construction, Urban Engineering Program, Federal \\ University of Rio de Janeiro, UFRJ, Brazil \\ ${ }^{2}$ Department of Architecture and Urbanism, \\ Federal Rural University of Rio de Janeiro, UFRRJ, Brazil \\ ${ }^{3}$ Post-Graduation Program on Civil Engineering, \\ Federal University of Rio de Janeiro, COPPE/UFRJ, Brazil \\ ${ }^{4}$ Post-Graduation Program on Energy Planning, \\ Federal University of Rio de Janeiro, COPPE/UFRJ, Brazil
}

\begin{abstract}
The concept of planning more sustainable cities is a global concern, facing current prominent environmental chaos. The construction industry is, among others, responsible for the destruction of the environment, due to the extraction of raw material for the manufacture of construction elements, debris generation during the process of construction and high energy consumption throughout the life cycle of the buildings.

Thus, this paper aims to propose a possibility of low environmental impact construction, proposing the incorporation of bioclimatic conditions in architectural works, minimizing environmental impacts. This research intends to promote the increase of buildings with reduced environmental impact and healthier cities, by employing systems for natural lighting and natural ventilation, as simple and cheap solutions, often seen only by formal feature (project design), without the use of high-cost technologies and complexity. A case study was conducted regarding the Spanish building Solar Hemicycle, due to its contemporary bioclimatic design that meets the current needs of society. The case study based on the Solar Hemicycle demonstrates the good
\end{abstract}


performance of bioclimatic architecture, illustrating that it is possible to combine architectural practice (incorporating passive systems in architectural projects), to the environment, towards environmental sustainability without high investments in technology. The results of the study provide architecture and civil engineering professionals access to eco-efficient solutions for application in future projects, and thus contribute to the appearance of buildings that provide a higher quality of life for people and harmony with the environment.

Keywords: bioclimatic architecture, sustainable building, passive systems, Solar Hemicycle (Spain).

\section{Introduction}

Environmental degradation caused by the indiscriminate use of natural resources started in the Industrial Revolution, in the eighteenth century, with the increasing demand for goods and services generated by the capitalist society (Zambrano [1]). Parallel to the industrial revolution began a rapid process of human migration to the city in search of better living conditions. But the civilization development and industrial capacity did not accompany the speed of the migration process, which resulted in unemployment, social inequality and subhuman quality of life (Freitas [2]).

On the European continent, in the nineteenth century, the struggle for social, political and spatial reforms began, in search of solutions to meet the needs of the poor sector of the society for housing, urban infrastructure and, above all, for quality of life. During this period, there were several proposals and urban achievements in Europe, including, from the perspective of sustainable urban development, the "Garden City" from the English Ebenezer Howard (Andrade [3]). The ideals proposed by Howard emerged in a period when discussions on sustainable development and ecology had not been exposed, however the idea of the "Garden Cities" already presents a concern with the environmental impacts caused by urban development [3].

Various European countries encouraged by the urgency of the need for organization and spatial planning, in the twentieth century, adopted urban models similar to Howard, with a socio-environmental focus, prioritizing environmental conservation and regional planning measures. Thus, in the postwar world, the concept of the Garden City became a tool for building new cities in England.

However, the immediate need to enable a greater number of housing units to meet the needs of the population affected by the conflicts fled the standard of spatial limitation and population imposed by the philosophy established by Howard. This new context led to the generation of new programs that could meet, besides the sustainability of the built environment, the amount of immediate housing. The effect of this redesign caused the spatial suburbanization of new cities, as these proposals, known as the New Towns Act, were based on the zoning of cities on commercial, industrial and residential bands, quite apart, which brought new needs: the automobile and, with it, environmental pollution, deforestation (open roads), concentration of poverty in 
central areas (population lacking of purchasing power to buy a car), the decrease of interaction between the different markets [3].

The city can be characterized as a complex ecosystem comprised of a set of organisms that interrelate with nature. Based on this premise, the unit built can be considered a living organism subject to changes, whether heat (natural ventilation), energy (solar collection) or fluid (capturing rainwater and gray water reuse). The unit built is the foundation of the formation of the city, and dissemination of units that provide less environmental impact is essential to promote sustainable urban development.

The construction industry has an important role in the design of urban space, being responsible for the formation of the infrastructure essential to the continuity of the process of city development, by building bridges, roads, industries, buildings and other elements from the urban environment. The existence of such devices has brought improvements on the quality of life by providing options including displacement, housing, commerce, recreation, but it also has been causing increased power consumption, extraction of raw materials, generation of debris, air, soil and water pollution, causing irreparable damage to the environment . The construction of large real estate projects can impact quite negatively nature, thus the use of bioclimatic construction techniques on these units. The Solar Hemicycle building, located in Madrid, was designed considering assumptions based on the concept of bioclimatic architecture, which incorporated climatic factors in the operation of the building, such as the use of resources for passive solar energy, natural ventilation and lighting.

\section{Objective}

The concept of sustainable development is increasingly indispensable opposite the current scenario of the collapsing environment. This research is embedded in the theme of sustainability applied to the construction industry, and it is intended to analyze possibilities and benefits of projects with bioclimatic characteristics. Thus, this work is justified by the need to study the feasibility of incorporating environmental factors in architectural projects, aiming, even as theory, to reduce the environmental impacts from the construction and improve quality of life within the population. The scientific contribution of this work consists on promoting sustainability in the built environment from the proposed merger of assumptions that lead to a construction with a low-impact on the environment. In Brazil there are still no regulations and guidelines requiring minimum performance in housing programs able to deliver the built quality, durability and environmental sustainability. The material produced by this work is accounted to be used in future studies on the topic, or to be complemented in subsequent research.

\section{Methodology}

In order to investigate more precisely the characteristics of bioclimatic architecture, the Solar Hemicycle, located in Móstoles (Madrid, ES), was 
selected as an example. The case study shows that design characteristics were based on environmental factors regarding the region it was built, bringing benefits to the built environment and the population.

The research methodology adopted was based on international models to provide data that bring application possibilities in the Brazilian context, in order to improve the quality of the life cycle of the building and minimize environmental impacts originated from national construction.

A case study was performed in a multifamily building in Europe - the Spanish Solar Hemicycle building, considering that in the Brazilian context, to this architectural typology, there are few contemporary designs that take into account the premise of bioclimatology product design. This research aims to promote the increase of buildings with reduced adverse environmental impact and healthier cities, by employing passive systems for natural lighting and ventilation, as simple and cheap solutions, often appearing only as formal feature (project design), without the use of expensive and complex technologies. The results of the study provide information for the discussion and recommendations of bioclimatic buildings in Brazilian projects.

In countries like Brazil, where the climate and geography are conducive to bioclimatic architecture, it becomes a very viable option, especially in terms of value, where the deployment of passive systems is often almost zero cost, treating it only as a strategy to be adopted in project design.

\section{Bioclimatic architecture}

Bioclimatic architecture is based on a sustainable way of designing, considering the natural terrain features (climate, fauna, flora, topography, among others), as variables for the development of design solutions, providing a balance between natural environment and built environment by selecting solutions from renewable energy sources (energy efficiency), raw materials and building systems with low environmental impact. The purpose of the bioclimatic architecture is to minimize the environmental damage caused by construction and thus provide better comfort and quality of life to society.

Bioclimatic architecture, also known as passive solar architecture, aims at energy efficiency, reduced environmental impact and hygrothermal comfort by harmonizing buildings with the physical characteristics of the terrain (weather, sunlight, prevailing winds, vegetation and topography). This balance between building and environment starts from the artifices of project design that allow maximum utilization of the natural conditions of the area surrounding the building (Russi et al. [4]).

Bioclimatic architecture has its origin in Bioclimatology, the science that has as its object the study of the interactions between the biosphere and atmosphere, based on climatology. Through bioclimatic architecture, relations between man and nature are optimized, both regarding the reduction of environmental impact in improving quality of human life through environmental comfort and rationalization of energy consumption. 
The understanding of the climate and geography of the region can be considered essential in planning a bioclimatic design. The climatological study enables the application of passive systems for natural lighting and ventilation, since the environment can be designed according to the weather, avoiding the energy consumption for air conditioning equipment for artificial environment, while offering the best comfort conditions man.

According to Roaf [5], three principles should be applied to all building projects: the first, "design for the environment", the second "design for the social and physical environment" and the third "design for time" (day/night, season, life cycle, etc.).

Since natural ventilation is an important tool to maintain thermal comfort and health of the environment (cooling and dehumidification), the identification of the prevailing winds at the site must be performed early in the process of bioclimatic design, availing passive in the building, allowing the circulation of air through openings in the building, causing effects such as cross ventilation and chimney (Mascarello [6]). Another important factor to be considered in bioclimatic projects is the study of solar geometry (solar trajectory), which serves to identify the best location of the building relative to the sun throughout the year. The understanding of the solar position as of the building is able to indicate the possible projections of shaded areas or penetration of sunlight, these items may result in thermal loads on the building (Mascarello [6]).

\section{Case study}

The case study selected was the Solar Hemicycle building, located in Madrid (Spain), in the city of Sur Mosteles (Figure 1 indicates its location and shows its main facade). The Solar Hemicycle, designed by 'Ruiz-Larrea and Associates Architecture' is the result of a restricted concurrence (for invited teams), organized in 2004 by the local Municipal Institute of Lands. Its construction was completed in 2009, but since the design phase it has been gaining recognition for good projective practices that include sustainable and bioclimatic characteristics, also ensuring architectural awards and distinctions, including first prize in Sustainable Building of Castile and Leon in 2010, first place in 2010 ENDESA, the distinction COAM 2010 and the first in ASPRIMA-SIMA 2010 (Larrea et al. [7]).

Spain is one of the pioneers in research of bioclimatic architecture, being known worldwide in this area; also applying techniques in social housing projects.

The Solar Hemicycle consists of 92 housing units, arranged in six floors, with attic, basement, 118 parking spaces and leisure area, occupying a total area of 11 thousand square meters. It has the form of a tape in an arc (semicircle) accompanying the daily movement of the sun in order to collect solar rays, in the winter, and, in the summer, produce shaded areas, promoting the thermal comfort of the building. Furthermore, the shape of the building and its positioning on the site provide natural ventilation and lighting, minimizing power consumption [7]. 
The Solar Hemicycle can be considered a sustainable building, not for its raw materials, since traditional materials were used for cheaper construction, but by resorting to passive and active strategies for saving energy and reducing $\mathrm{CO}_{2}$ emissions (approximately, 87\% less than the traditional buildings), however it is more appropriate to identify it with a bioclimatic building [7].



Figure 1: Location and main facade of the Solar Hemicycle. (Source: Ruiz Larrea and Associates, 2010.)

The south facade (Figure 2), designed as a "solar collector", is lined with moving brise soleils in front of the windows of the apartments. This mechanism helps in projecting shadows and controlling input of sunlight inside, allowing the entry of sunlight radiation throughout the year, according to the user's needs.

Figure 2 illustrates schematically how the brise soleil system of the building works. During the winter, the brise soleil can be collected, pulled up, allowing greater penetration of the sun inside, and therefore, more heat inside the residence. During the summer, the brise soleil panels should be kept closed in order to keep the internal environment cooler. The arrangement of the brise soleils fins favors convective motion of the air inside the room, providing cooling or heating throughout the year. The red arrows represent the movement of warm air and the blue arrows represent the movement of cold air [7].

The north facade, where the access corridors to the rooms are located (Figure 3), was designed to allow summer evening winds to refresh the building, but to protect from the cold temperatures of winter winds, polycarbonate panels were designed, which besides serving as a barrier to sound and wind allows the passage of light into the houses, without compromising privacy. 

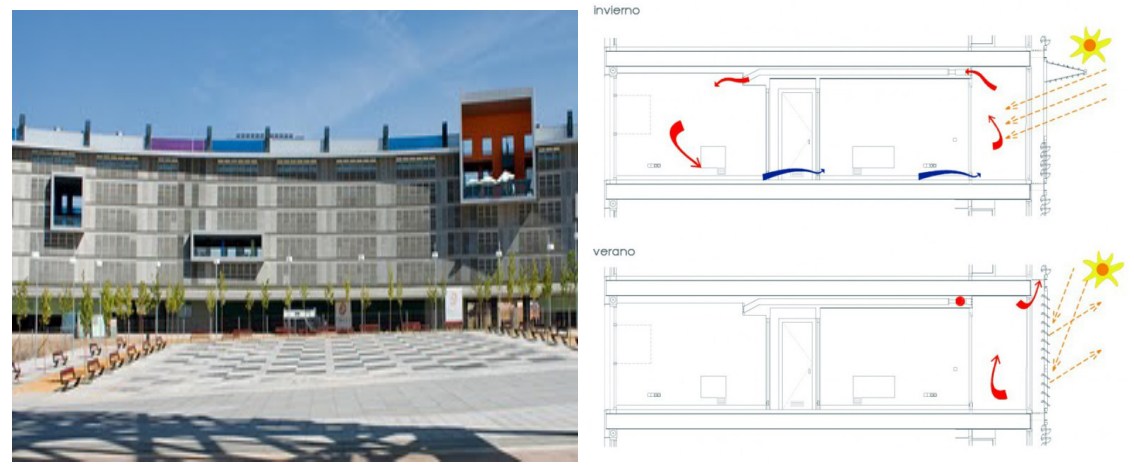

Figure 2: Solar Hemicycle south facade and schematic drawing of the solar rays and the use of the brise soleil. (Source: Ruiz Larrea and Associates, 2010.)

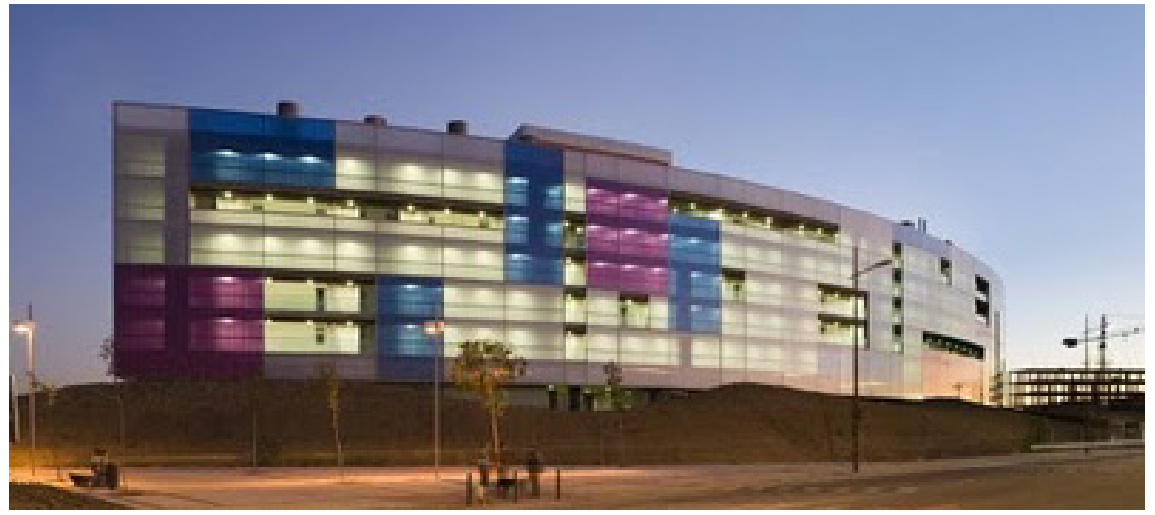

Figure 3: Solar Hemicycle north facade. (Source: Ruiz Larrea and Associates, 2010.)

One of the biggest reasons to study this construction among other Spanish bioclimatic buildings is the use of the passive system for natural cooling by Canadian wells, a geothermal heat exchanger based on the heat capacity of the soil, the temperature difference between the surface and the underground, with the objective of making the air circulation inside the earth, allowing cooling in summer and heating in winter, without the necessity of any artificial systems (heating and air conditioning). In housing units, the air is introduced preheated to $18^{\circ} \mathrm{C}$ (summer and winter), and distributed through pipes embedded in the walls and released by grills, close to the ground, located in the living room and bedrooms (Larrea et al. [7]). The air in the pipes circulates between 35 and 40 meters below the soil. At this depth temperature can be considered constant along the year, ranging from $14^{\circ} \mathrm{C}$ to $16^{\circ} \mathrm{C}$. This system reduces about $60 \%$ of the energy consumption of the building, since the energy used by the UTAs is 
very low, directed only to the operation of the air circulators - fans that distribute the air obtained from the Canadians wells to the apartments and common areas of the building [7] . Figure 4 shows, schematically, the system of Canadian wells, located near the north facade, where there is greater ventilation.

In Figure 4, the blue arrows represent the cold winds and the red arrows represent the hot winds. During the winter the cold air is collected by the Canadian wells and driven by vertical pipes to the top of the building, where they are released, preventing cooling of environments during periods where the demand is for heating. The galleries located in the south facade capture heat from the sun rays and distributes to the indoor environment through the circulation pipes. In case the heat from natural sources does not reach the desired temperature, the apartments are equipped with electric heaters.

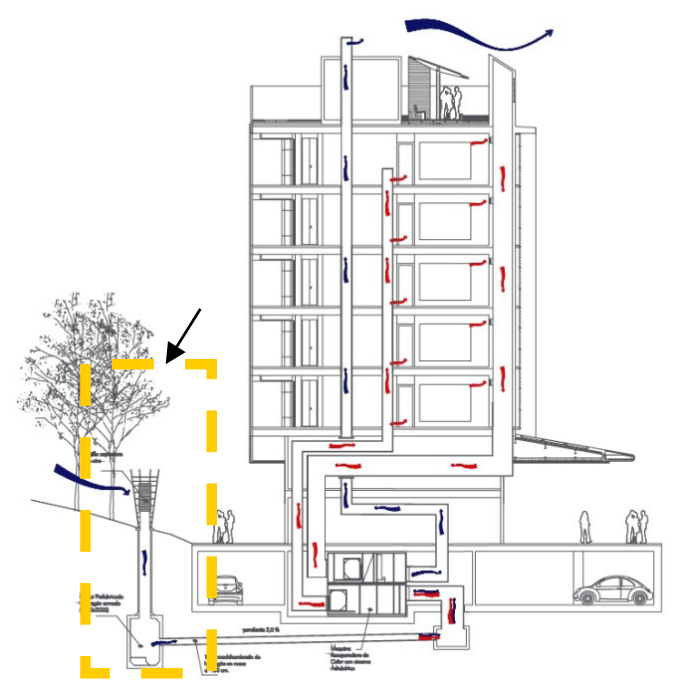

Figure 4: Schematic figure representing the operation of Canadian wells during winter. (Source: Ruiz Larrea and Associates, 2010.)

\section{Final considerations}

The bioclimatic architecture contributes to the buildings energy efficiency as it takes advantage of passive ventilation and lighting techniques, allowing the HVAC and lighting of indoor environments without excessive consumption of electricity. In many cases, it allows the complete annulment of the need for electricity distribution, depending only on solar energy for their supplies. For this to occur, it is only necessary that the architectural design is suited to the climate of the region in which it will be implemented, in compliance with the local solar guidelines and geography.

Bioclimatic strategies applied to construction go beyond issues of environmental comfort and energy efficiency. The sum of the characteristics 
of the projects to their bioclimatic variables (materials, clean energy, water use and other), have been increasingly explored with the intention of minimizing environmental impacts.

The example of the Solar Hemicycle building demonstrates the performance of bioclimatic architecture, illustrating that it is possible to combine good architectural practices (incorporating passive systems in architectural designs), to the environment in support of environmental sustainability, without high investments on technology. In countries like Brazil, where the climate and geography are conducive to bioclimatic architecture, it becomes a very viable option, especially in terms of value, where the deployment of passive systems is often almost zero cost, being treated only as favorable deployment.

The building is a very important element to urban sustainability, optimizing the use of resources like water and energy. These resources, when originated in bioclimatic projects, are reversed in savings for consumers, preserving the environment and better quality of life. The dissemination of this important concept can minimize environmental impacts.

\section{References}

[1] Zambrano, L. M. A. Integração dos Princípios da Sustentabilidade ao Projeto de Arquitetura. Thesis. PROARQ - Programa de Pós-Graduação em Arquitetura. UFRJ - Universidade Federal do Rio de Janeiro. February, 2008.

[2] Freitas, C. G. L. Habitação e Meio Ambiente - Abordagem Integrada em Empreendimentos de Interesse Social. Coleção Habitare. São Paulo: IPT, 2001.

[3] Andrade, L. M. S. O Conceito de Cidades-Jardins: Uma Adaptação para as Cidades Sustentáveis. Vitruvius. Arquitextos. Ano IV. November, 2003. Available in: <http://vitruvius.com.br/revistas/read/arquitextos/04.042/637>. Accessed: October 15, 2010.

[4] Russi, M., Santos, J. P. and Vettorazzi, E. A utilização de estratégias passivas de conforto térmico e eficiência energética para o desenvolvimento de uma habitação unifamiliar. In: Anais - Congresso Internacional Sustentabilidade e Habitação de Interesse Social. Porto Alegre - RS, 2010.

[5] Roaf, S. Ecohouse: A Casa Ambientalmente Sustentável. $2^{\text {on }}$. Edition. Porto Alegre, Bookman, 2006.

[6] Mascarello, V. L. D. Princípios Bioclimáticos e Princípios de Arquitetura Moderna: Evidências no Edificio Hospitalar. Dissertation (Master on Architecture). Program of Research and post graduation on Architecture. Universidade Federal do Rio Grande do Sul, 2005.

[7] Larrea, C. R., Gómez, A. and Prieto E. Hemiciclo Solar: La Energía Como Material Del Proyecto de Arquitectura. FATECSA OBRAS S.A.U.: Madrid, 2010, il.col. 